\title{
Perbedaan Microsoft Power Point 2003, 2007, 2010, dan 2013
}

\author{
M. Yunus Dwi A ${ }^{1 *}$, Nurul Fadilah ${ }^{1}$, Fransiska Okta ${ }^{1}$, Istatik Fadilah ${ }^{1}$, Frismoreka ${ }^{1}$, \\ Mariana Ap ${ }^{1}$, M. Lutfi Hasan ${ }^{1}$, Nadia Fara A.K.S ${ }^{1}$, Nevita Lexia ${ }^{1}$, Nyai \\ Andriani ${ }^{1}$, Pradita Kusuma ${ }^{1}$, Khoirul Ngibad ${ }^{2}$ \\ ${ }^{1}$ Mahasiswa D3 Teknologi Laboratorium Medik Universitas Maarif Hasyim Latif Sidoarjo \\ ${ }^{2}$ Dosen D3 Teknologi Laboratorium Medik Universitas Maarif Hasyim Latif Sidoarjo \\ *Email : yunus.uchiha26@gmail.com
}

\section{Microsoft PowerPoint}

Microsoft PowerPoint atau Microsoft Office PowerPoint atau PowerPoint adalah sebuah program komputer untuk presentasi yang dikembangkan oleh Microsoft di dalam paket aplikasi kantoran mereka, Microsoft Office, selain Microsoft Word, Excel, Access dan beberapa program lainnya. PowerPoint berjalan di atas komputer PC berbasis sistem operasi Microsoft Windows dan juga Apple Macintosh yang menggunakan sistem operasi Apple Mac OS, meskipun pada awalnya aplikasi ini berjalan di atas sistem operasi Xenix. Aplikasi ini sangat banyak digunakan, apalagi oleh kalangan perkantoran dan pebisnis, para pendidik, siswa, dan trainer. Dimulai pada versi Microsoft Office System 2003, Microsoft mengganti nama dari sebelumnya Microsoft PowerPoint saja menjadi Microsoft Office PowerPoint. Lalu, pada Office 2013, namanya cukup disingkat PowerPoint. Versi terbaru dari PowerPoint adalah versi 15 (Microsoft Office PowerPoint 2013), yang tergabung ke dalam paket Microsoft Office 2013.

$\underline{\text { Sejarah }}$

Aplikasi Microsoft PowerPoint ini pertama kali dikembangkan oleh Bob Gaskins dan Dennis Austin sebagai Presenter untuk perusahaan bernama Forethought, Inc yang kemudian mereka ubah namanya menjadi PowerPoint.

Pada tahun 1987, PowerPoint versi 1.0 dirilis, dan komputer yang didukungnya adalah Apple Macintosh. Pada waktu itu, PowerPoint masih menggunakan warna hitam/putih, yang mampu membuat halaman teks dan grafik untuk transparansi overhead projector (OHP). Setahun kemudian, versi baru dari PowerPoint muncul dengan dukungan warna, setelah Macintosh berwarna muncul ke pasaran.

Microsoft pun mengakuisisi Forethought, Inc dan tentu saja perangkat lunak PowerPoint dengan harga kira-kira 14 Juta dolar pada tanggal 31 Juli 1987. Pada tahun 1990, versi 
Microsoft Windows dari PowerPoint (versi 2.0) muncul ke pasaran, mengikuti jejak Microsoft Windows 3.0. Sejak tahun 1990, PowerPoint telah menjadi bagian standar yang tidak terpisahkan dalam paket aplikasi kantoran Microsoft Office System (kecuali Basic Edition).

Versi terbaru adalah Microsoft Office PowerPoint 2013 (PowerPoint 15). Versi ini dirilis pada bulan Januari 2013, yang merupakan sebuah lompatan yang cukup jauh dari segi antarmuka pengguna dan kemampuan grafik yang ditingkatkan. Selain itu, dibandingkan dengan format data sebelumnya yang merupakan data biner dengan ekstensi *.ppt, versi ini menawarkan format data XML dengan ekstensi *.pptx

\section{$\underline{\text { Versi }}$}

\begin{tabular}{|c|c|c|c|}
\hline Tahun & Versi PowerPoint & Sistem Operasi & $\begin{array}{c}\text { Paket Microsoft } \\
\text { Office }\end{array}$ \\
\hline 1987 & PowerPoint 1.0 & Mac OS classic & T/A \\
\hline 1988 & PowerPoint 2.0 & Mac OS classic & T/A \\
\hline 1990 & PowerPoint 2.0 & Windows 3.0 & T/A \\
\hline 1992 & PowerPoint 3.0 & Mac OS classic & T/A \\
\hline 1992 & PowerPoint 3.0 & Windows 3.1 & T/A \\
\hline 1993 & PowerPoint 4.0 & $\begin{array}{c}\text { Windows NT 3.1, Windows } 3.1 \text {, } \\
\text { Windows } 3.11\end{array}$ & Microsoft Office 4.x \\
\hline 1994 & PowerPoint 4.0 & Mac OS classic & T/A \\
\hline 1995 & $\begin{array}{l}\text { PowerPoint } 7 \text { for } \\
\text { Windows } 95\end{array}$ & Windows 95, Windows NT & Microsoft Office 95 \\
\hline 1997 & PowerPoint 97 & Windows 95/98, Windows NT 4.0 & Microsoft Office 97 \\
\hline 1998 & PowerPoint 98 & Mac OS Classic & $\begin{array}{c}\text { Microsoft Office } \\
1998 \text { for Mac } \\
\end{array}$ \\
\hline 1999 & PowerPoint 2000 & $\begin{array}{c}\text { Microsoft Windows 98, Windows NT } \\
\text { 4.0, Windows } 2000\end{array}$ & $\begin{array}{l}\text { Microsoft Office } \\
2000 \\
\end{array}$ \\
\hline 2000 & PowerPoint 2001 & Mac OS X & $\begin{array}{c}\text { Microsoft Office } \\
2001 \text { for Mac }\end{array}$ \\
\hline 2001 & PowerPoint 2002 & Windows 2000/XP & Microsoft Office XP \\
\hline 2002 & PowerPoint v.X & Mac OS X & $\begin{array}{c}\text { Microsoft } \\
\text { Office:mac v.X }\end{array}$ \\
\hline 2003 & PowerPoint 2003 & $\begin{array}{c}\text { Windows } 2000 \text { Service Pack 3, } \\
\text { Windows XP Service Pack 1, Windows } \\
\text { Server } 2003\end{array}$ & $\begin{array}{l}\text { Microsoft Office } \\
\text { System } 2003\end{array}$ \\
\hline 2004 & PowerPoint 2004 & Mac OS X & $\begin{array}{c}\text { Microsoft } \\
\text { Office:mac } 2004\end{array}$ \\
\hline 2006 & PowerPoint 2007 & $\begin{array}{l}\text { Microsoft Windows Vista, Windows } \\
\text { XP Service Pack 2, Windows Server } \\
\text { 2003, Windows Server } 2008\end{array}$ & $\begin{array}{l}\text { Microsoft Office } \\
\text { System } 2007\end{array}$ \\
\hline
\end{tabular}


Posted: June 30, 2018

\begin{tabular}{|c|c|c|c|}
\hline 2007 & PowerPoint 2008 & Mac OS X & $\begin{array}{c}\text { Microsoft } \\
\text { Office:mac 2008 }\end{array}$ \\
\hline 2010 & PowerPoint 2010 & $\begin{array}{c}\text { Windows 7 (Disarankan), Windows } \\
\text { Vista (Service Pack 2), Windows XP } \\
\text { (Service Pack 3) Windows Server 2008, } \\
\text { Windows Server 2008 R2 }\end{array}$ & $\begin{array}{c}\text { Microsoft Office } \\
2010\end{array}$ \\
\hline 2010 & PowerPoint 2011 & Mac OS X & $\begin{array}{c}\text { Microsoft } \\
\text { Office:mac 2011 }\end{array}$ \\
\hline 2013 & PowerPoint 2013 & $\begin{array}{c}\text { Windows 8 (Disarankan), Windows 7, } \\
\text { Windows Server 2008 R2, Windows } \\
\text { Server 2012, Mac OS X (Office 365) }\end{array}$ & $\begin{array}{c}\text { Microsoft Office } \\
\text { 2013 \& Office 365 }\end{array}$ \\
\hline
\end{tabular}

\section{Operasi}

Dalam PowerPoint, seperti halnya perangkat lunak pengolah presentasi lainnya, objek teks, grafik, video, suara, dan objek-objek lainnya diposisikan dalam beberapa halaman individual yang disebut dengan "slide". Istilah slide dalam PowerPoint ini memiliki analogi yang sama dengan slide dalam proyektor biasa, yang telah kuno, akibat munculnya perangkat lunak komputer yang mampu mengolah presentasi semacam PowerPoint dan Impress. Setiap slide dapat dicetak atau ditampilkan dalam layar dan dapat dinavigasikan melalui perintah dari si presenter. Slide juga dapat membentuk dasar webcast (sebuah siaran di World Wide Web). PowerPoint menawarkan dua jenis properti pergerakan, yakni Custom Animations dan Transition. Properti pergerakan Entrance, Emphasis, dan Exit objek dalam sebuah slide dapat diatur oleh Custom Animation, sementara Transition mengatur pergerakan dari satu slide ke slide lainnya. Semuanya dapat dianimaskan dalam banyak cara. Desain keseluruhan dari sebuah presentasi dapat diatur dengan menggunakaan Master Slide, dan struktur keseluruhan dari prsentasi dapat disunting dengan menggunakan Primitive Outliner (Outline).

PowerPoint dapat menyimpan presentasi dalam beberapa format, yakni sebagai berikut:

- *.PPT (PowerPoint Presentation), yang merupakan data biner dan tersedia dalam semua versi PowerPoint (termasuk PowerPoint 12)

- *.PPS (PowerPoint Show), yang merupakan data biner dan tersedia dalam semua versi PowerPoint (termasuk PowerPoint 12)

- *.POT (PowerPoint Template), yang merupakan data biner dan tersedia dalam semua versi PowerPoint (termasuk PowerPoint 12)

- *.PPTX (PowerPoint Presentation), yang yang merupakan data dalam bentuk XML dan hanya tersedia dalam PowerPoint 12. 


\section{$\underline{\text { Kompatibilitas }}$}

PowerPoint memiliki fitur untuk memasukkan konten dari aplikasi lainnya yang mendukung Object Linking and Embedding (OLE), beberapa presentasi sangat bergantung pada platform Windows, berarti aplikasi lainnya, bahkan PowerPoint untuk Macintosh sekalipun akan susah untuk membuka presentasi tersebut, dan bahkan kadang-kadang tidak dapat membukanya secara sukses dalam Macintosh. Hal ini mengakibatkan adanya kecenderungan para pengguna untuk menggunakan format dengan struktur data yang terbuka, seperti halnya Portable Document Format (PDF) dan juga OpenDocument dari OASIS yang digunakan oleh OpenOffice.org dan tentunya meninggalkan PowerPoint. Walaupun Begitu, Microsoft sudah melakukan hal serupa saat merilis format presentasi berbasis XML (PowerPoint 12).

\section{Perbedaan Power Point 2003-2013}

\section{Microsoft Office Power Point 2003}

- Masih ada menu File

- Menu pulldown

- Terdapat pembatas pada toolbar tapi lebih jelas 2007

- Smart Art, translation kurang lengkap

- Formatnya .ppt

- Toolbarnya ditampilkan secara vertical

- Tidak ada menu Home

- Tidak ada Quick Access Toolbar 
Posted: June 30, 2018

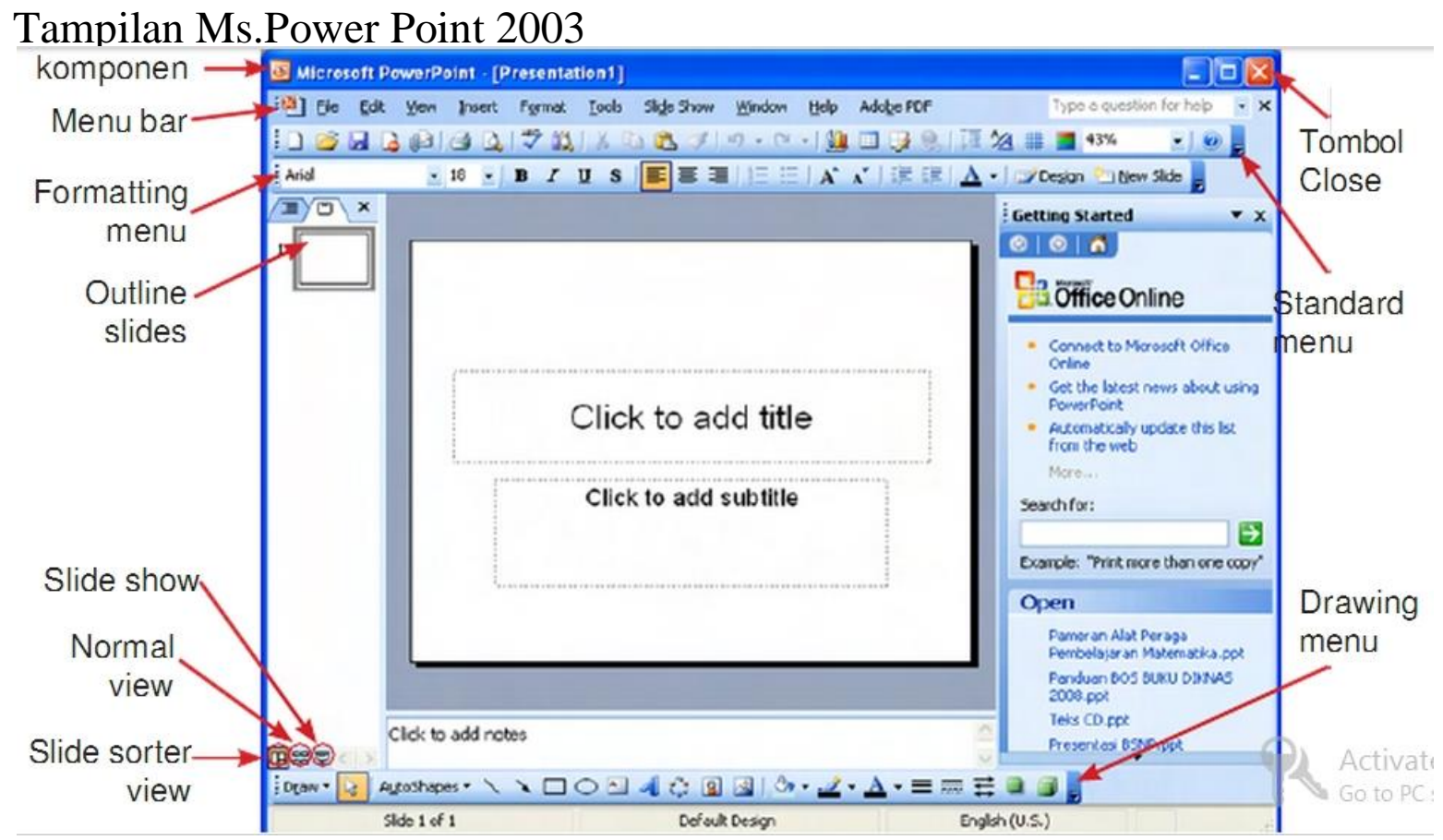

\section{Microsoft Office Power Point 2007}

- Adanya office button

- Menu Ribbon

- Pada ribbon terdapat pembatas yg jelas

- Smart Art, translation lebih lengkap dibanding 2003

- Formatnya .pptx

- Toolbarnya ditampilkan secara horizontal

- Ada menu Home

- Ada quick Access Toolbar 
Posted: June 30, 2018

Tampilan Ms.Power Point 2007

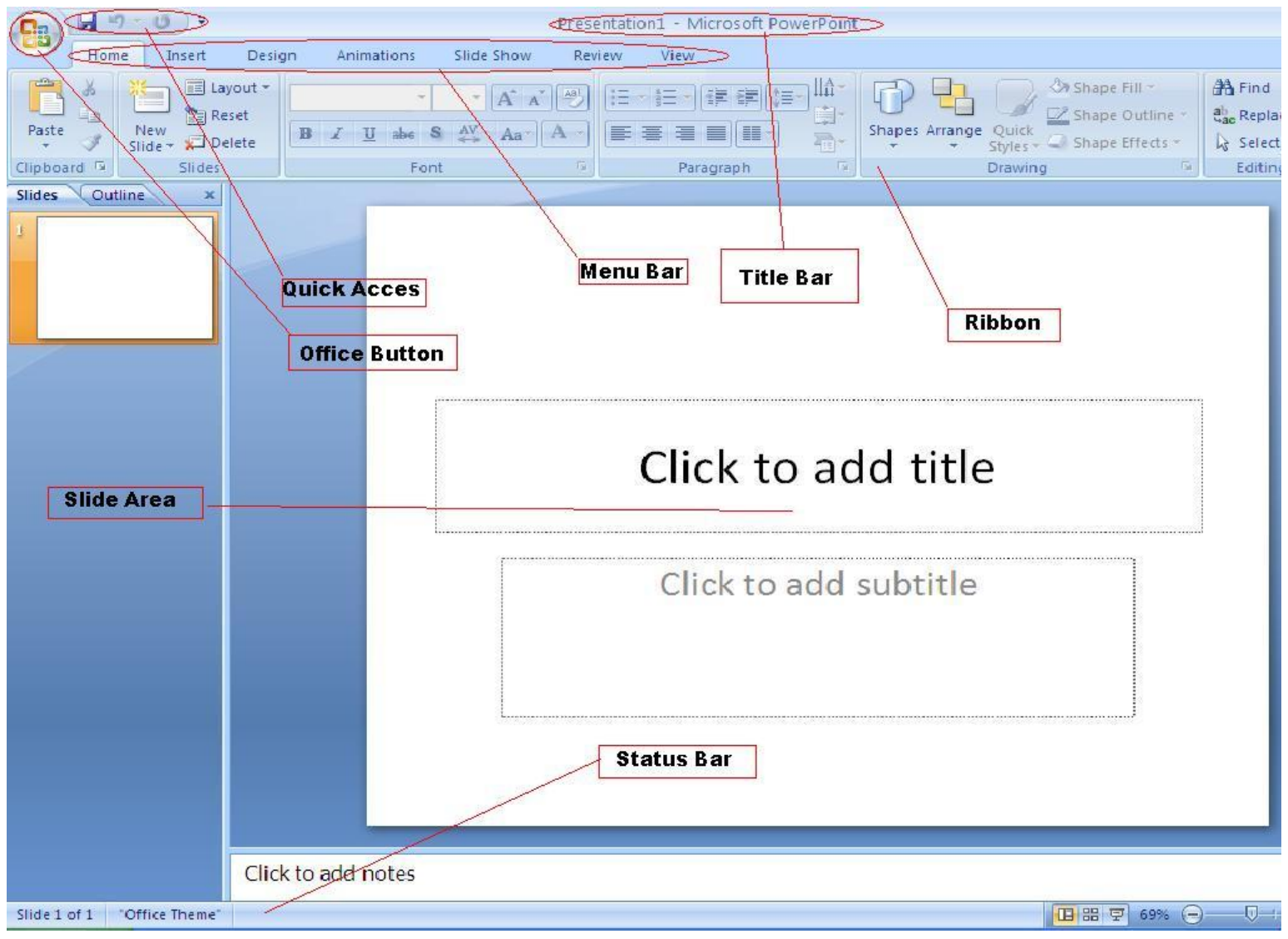

- Toolbarnya ditampilkan secara horizontal

- Ada menu Home

- Ada quick Access Toolbar 
Tampilan Ms.Power Point 2010

\section{BAGIAN-BAGIAN UTAMA LAYAR POWER POINT 2010}

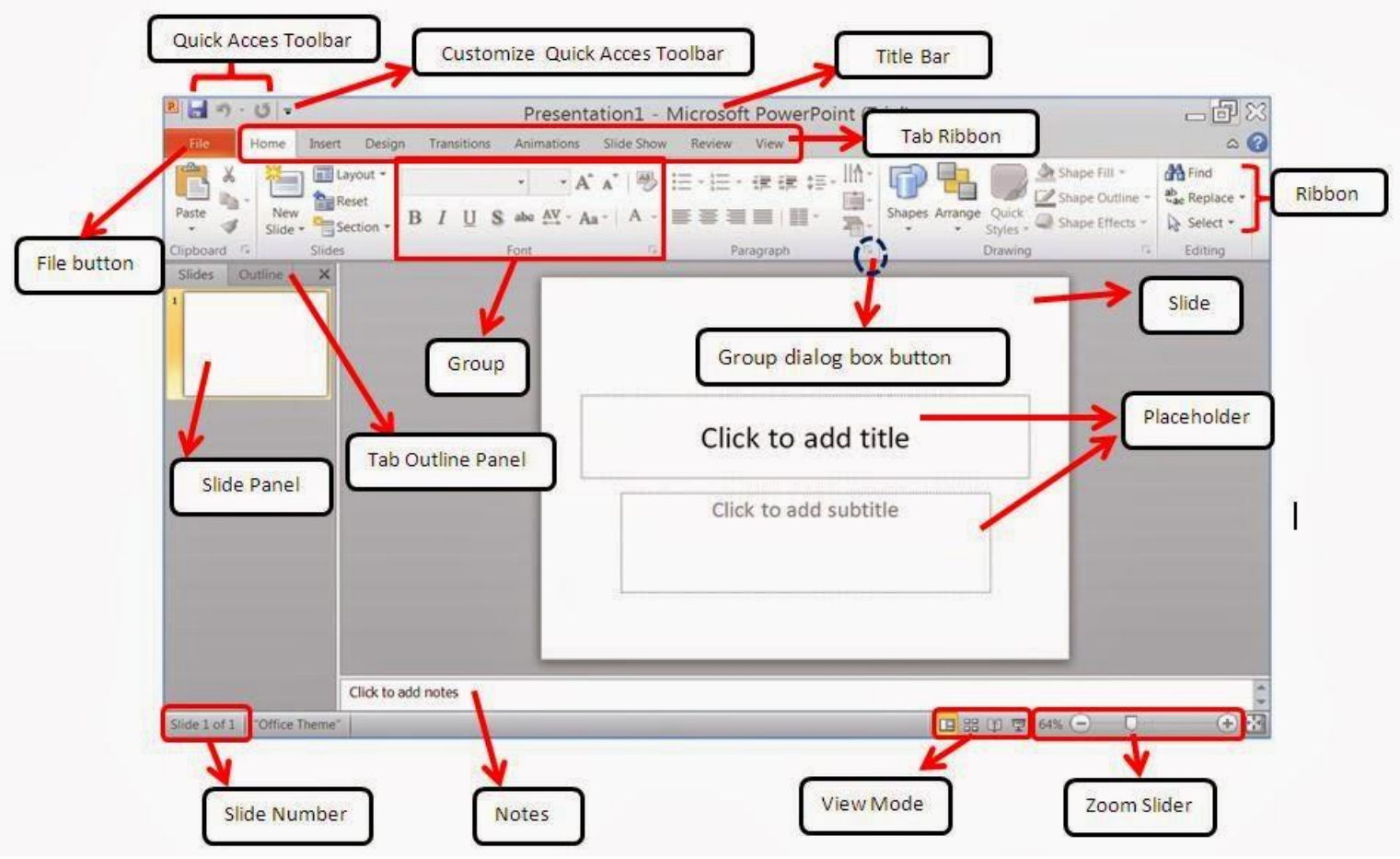

\section{Microsoft Office Power Point 2013}

- Ada menu File dan Home

- Menu Ribbon

- Pada ribbon Pembatasnya tidak jelas

- Content yg terdiri dr design, smart art, translation lebih lengkap

- Formatnya .pptx

- Toolbarnya ditampilkan secara horizontal

- Ada menu Home

- Ada quick Access Toolbar 
Posted: June 30, 2018

Tampilan Ms.Power Point 2013

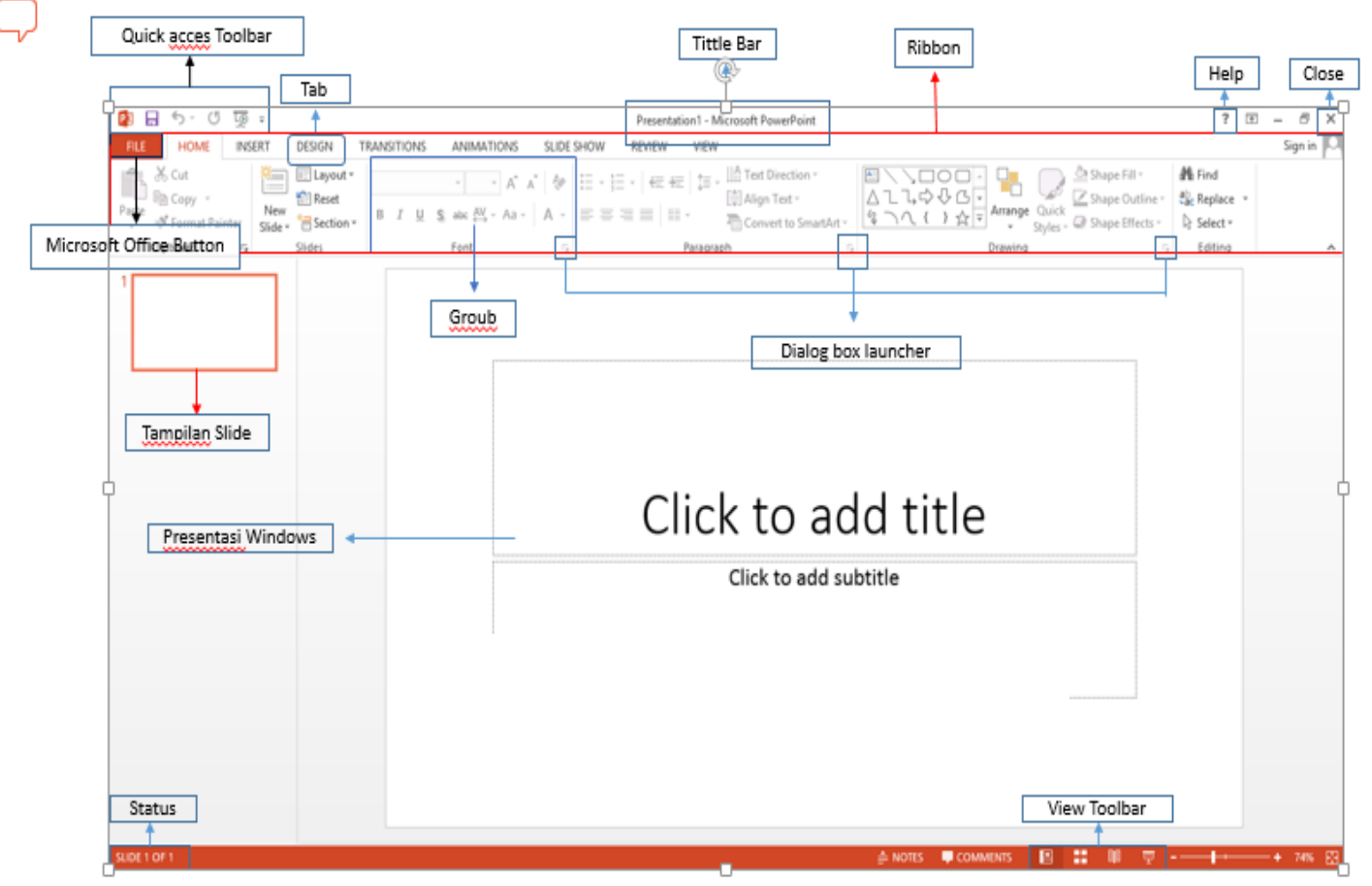

\section{Daftar Pustaka}

Ngibad, K. (2018, February 28). Fungsi Menu-Menu Microsoft Word 2013.

https://doi.org/10.17605/OSF.IO/AZ5BG 